\title{
Gremio, democracia y asociatividad: el Colegio de Periodistas de Chile ante los comunicadores de hoy.
}

\author{
Dra. Claudia Mellado Ruiz \\ Departamento de Comunicación Social - Universidad de Concepción \\ claudiamellado@udec.cl \\ Sergio Barría Oyarzún \\ Licenciado en Comunicación Social - Universidad de Concepción \\ Felipe Besoain Flores \\ Estudiante de Periodismo - Universidad de Concepción \\ Jorge Enríquez Carrera \\ Licenciado en Comunicación Social - Universidad de Concepción
}

Proyecto DIUC 205.174.002-1.0

Realidad laboral, asociativa y profesional de los periodistas de la Octava Región

\section{Resumen}

La baja asociatividad que presenta el Colegio de Periodistas, plantea dudas respecto a la real vigilancia democrática e injerencia en la vida pública de un gremio debilitado. En efecto, la asociatividad de los profesionales es baja en comparación a gremios similares; registrando sólo un 2,9\% del total de egresados en la Octava Región durante los últimos cinco años, cifra similar al resto del país.

Esta realidad implica una responsabilidad de la propia entidad, por cuanto el colegio desconoce el creciente protagonismo de los periodistas en el ámbito organizacional y corporativo - de hecho un $64 \%$ de los profesionales de la región se desempeña en estas áreas-, existiendo una evidente despreocupación por cautivar y comprometer a aquéllos no vinculados al periodismo tradicional.

En síntesis, la crisis de representatividad en que se encuentran los periodistas cuestiona su rol social, el carácter del Colegio y -más aún- la formación profesional misma.

\section{Abstract}

The low associability around Colegio de Periodistas, states serious doubts about the real democratic vigilance and influence into the public life of a weakened guild. In fact, the journalists' associability is down compared to similar guilds, whit just a $2.9 \%$ to the total of graduates in the Eighth Region during last five years, similar quantity in the rest of the country.

This reality implicates a responsibility from the Colegio de Periodistas, because the entity don't know the journalists' increasing leading into the organizational and corporative area - in fact, a $64 \%$ from the Eighth Region professionals work on these areas- showing an evident unconcern to charm and compromise to those non-linked at the traditional journalism.

In summary, the journalists' representatively crisis questions their social role, Colegio de Periodistas' character and more over professional formation itself.

Palabras clave: Asociatividad, vigilancia, democracia, Colegio de Periodistas.

Key words: Associability, vigilance, democracy, Colegio de Periodistas. 
Gremio, democracia y asociatividad...

\section{LA MISIÓN ASUMIDA}

as ideas ilustradas y el nuevo orden post-revolucionario posibilitaron enormemente el nacimiento de una "conciencia pública" entre los ciudadanos. Si bien el proceso tiene su origen más profundo en el secretismo de las instituciones del Antiguo Régimen, el reconocimiento del derecho a la información y al escrutinio de la gestión pública facilitaron la configuración de una "opinión pública". Su característica fue ser un ente activo, opinante en los asuntos públicos y fiscalizador ante eventuales abusos del poder institucional (Dader, 2001). En síntesis, el nacimiento de lo que hoy se caracteriza como "sociedad civil".

En esta primigenia forma de democracia liberal, la turbulencia de la esfera pública, así como la diversificación ideológica aceleran la formación de los medios de comunicación. De este modo, la prensa se transforma en el nexo entre el establishment político y la sociedad civil. Sea por omisión o por decisión, la prensa progresivamente reclamaría la potestad de vigilar la administración pública y el desarrollo democrático. En suma, el periodista hizo del derecho a la información y del ejercicio de la libertad de informar, su profesión (Desantes citado Gutierrez y Lavín, 2003). El ejercicio periodístico adquiere la misión de cautelar la transparencia, la probidad y el acceso a la información.

El director ejecutivo de Transparencia Internacional, David Nussbaum (2005), resume la relación del periodismo con la democracia afirmando que "si hay acceso a la información, hay transparencia y se evita la corrupción”. A su vez, la organización mundial concibe a la prensa como un organismo de control capaz para obligar a quienes detentan el poder a rendir cuentas y asegurar una sociedad transparente y responsable.

Esta misión se convertiría en el leit motiv del naciente oficio. El propio Colegio de Periodistas de Chile, establece que el rol de sus asociados es responder a las necesidades de información de la sociedad civil. Se identifica como condición sine qua non, un desempeño profesional apegado a la ética, independiente de intereses particulares, tendiente a la "defensa de los ciudadanos" y capaz de plasmar las opiniones de todos, "especialmente de los más postergados" (Conclusiones 12을 Congreso Colegio de Periodistas 2005).

Aun cuando desde la filosofía y neurobiología se establezca la imposibilidad de "ser la verdad" en la "praxis material", los periodistas la identifican como su primera y fundamental responsabilidad social, entendiendo que en ella -puntualmente en ellos- reside buena parte del orden democrático moderno.

\section{EN BÚSQUEDA DE MAYOR LIBERTAD Y TRANSPARENCIA}

La democracia contemporánea se fundamenta en el supuesto de responsabilidad de los poderes públicos ante la opinión pública, aspecto que requería que "lo público" fuera sometido a vigilancia para cautelar la transparencia. Empero, en el curso democrático, la relación entre el Estado y la prensa desembocó en una 
confrontación. Varios teóricos de la prensa la sindicarían como un "cuarto poder". Otros precisarían que es un "antipoder" al actuar como guardián de la probidad y transparencia democrática.

De hecho, Transparencia Internacional -a través de su director ejecutivo- reconoce a los medios como un "vehículo esencial" para un flujo de información, que en conjunto con la sociedad civil, obliga al poder político y empresarial a rendir cuentas de sus gestiones, al tiempo de mantenerles dentro de las márgenes legales. "La prensa puede jugar un papel importante en el combate de la corrupción por medio de investigaciones rigurosas sobre temas que afectan la calidad de un buen gobierno", resume Muzong Kodi, director para África y Asia de Transparencia Internacional. En tal sentido es de pleno consenso que sin una vigilancia de los medios de prensa y la sociedad civil, la corrupción aumentaría.

Sin embargo, "la reivindicación del derecho a una vigilancia social, que no sea patrimonio cerrado de las instituciones del Estado, plantea, por otra parte, contradicciones o riesgos de confusiones peligrosas para la salvaguardia de unos valores genuinamente democráticos" (Dader, 2001). Sobrevinieron entonces legislaciones restrictivas en torno al acceso a la información pública y la vida privada de las personalidades públicas. Entre los periodistas cundió el pavor del ocultamiento de potenciales irregularidades en la administración. Como respuesta, la prensa adoptó un carácter más agresivo, enarbolando la bandera de la libertad y la defensa ciudadana. Fue entonces cuando la profesión periodística se tornó más vulnerable. Según describe el periodista mexicano Juan Francisco Escobedo (2005), el gobernante se siente incómodo ante esta nueva actitud de la prensa, y en respuesta acciones inhibitorias, usando cuanto instrumentos legales e institucionales de que dispone. El periodista Jaime Silva afirmó en el 12ํㅡㄴ Congreso del Colegio de Periodistas de Chile que "la audacia de la prensa chilena en este nuevo escenario, tiene atemorizadas a las autoridades públicas, principalmente por las investigaciones periodísticas que han descubierto y denunciado redes, asociaciones ilícitas o conductas impropias, por lo cual se han creado una suerte de blindaje que pretenden legitimar a través de nuevas restricciones a las libertades de expresión e información". En tal sentido, Escobedo sentencia que "no hay nada más restrictivo de la libertad de expresión y prensa que la actitud intolerante de los gobernantes que usan (los tribunales de justicia) para inhibir el ejercicio periodístico y el derecho de la sociedad a estar informada acerca de cómo se ejercen las funciones y los recursos públicos" (Escobedo en Revista Mexicana de Comunicación, septiembre 2005: 47). Es en ese entorno de relaciones tensas e hiperventiladas, en que la verdad es la primera víctima.

De manera simultánea a la defensa de la transparencia, la prensa se ha abocado históricamente a la consecución de mayores espacios de libertad de expresión y menores restricciones a la investigación periodística. Entre las conclusiones emanadas del $12^{\circ}$ Congreso de Colegio de Periodistas destacan insistir ante el gobierno y parlamento en otorgar mayores libertades para la prensa al momento de exponer situaciones que afectaran la conducta y comportamiento de autoridades 
Gremio, democracia y asociatividad...

públicas, así como en devolver la tuición ética de sus profesionales a la orden. Concordamos en que las sociedades democráticas liberales deben eliminar de sus ordenamientos jurídicos las restricciones al ejercicio de la investigación periodística. Aún cuando ello exija previamente debatir los límites del espacio público. Discusión por cierto pendiente en Latinoamérica.

\section{ASOCIATIVIDAD DE LOS PERIODISTAS: CIFRAS Y EXPLICACIONES}

La historia del periodismo en Chile no es muy distinta de la que hubo de afrontar en otros países. Por varias décadas no contó de reconocimiento oficial y hasta la actualidad incluso, debe compartir su campo laboral con aprendices y profesionales de otras áreas. A ello se agrega las bajas remuneraciones que comúnmente se cancelan.

Los antecedentes remotos de sindicalización periodística en Chile surgen varias décadas antes del reconocimiento oficial de la profesión, cuando ya existía en el país un contingente de reporteros de oficio inspirados por principios éticos democráticos ligados al periodismo.

En la década de 1950, junto con la apertura de las primeras escuelas de periodismo, se crea el colegio profesional de la orden. Al menos hasta el golpe militar de 1973, al igual que los demás movimientos sindicales, es un actor importante en la vida política, que contó con una afiliación no menor.

La asociatividad, hasta entonces obligatoria para todos los titulados, es sustituida por una voluntaria; al tiempo que elimina la tuición ética con que contaban todos los colegios profesionales.

Los índices de asociatividad de los periodistas son bajos en comparación con otros gremios profesionales y con la tasa de sindicalización en Chile, que en todo caso no supera el $20 \%$ (Arrieta, 2003). Un estudio que realizan Mellado y otros (2005) en la Universidad de Concepción indica que sólo un 2,9\% de los egresados en el último quinquenio se afilió al Colegio, cifra similar a la situación nacional. En el Colegio se culpa a los efectos de la represión antisindical de la dictadura militar y la crisis global de representatividad y participación social. En general, la abulia tiende a atenuar al movimiento sindical y a diluir sus esfuerzos reivindicativos.

Este relativo "adormecimiento" del Colegio de Periodistas -y en general de todo el movimiento sindical- es la consecuencia de una complicada maraña de determinaciones y procesos.

La explicación a nivel de asociatividad se puede basar en distintos niveles. Una primera explicación es presentada por la escuela de elección racional que plantea que la asociación a un colectivo está vinculada a la percepción de obtener beneficios acordes al tiempo empleado (Mancur Olson, 1965). Aquí se plantea un problema circular, en cuanto que para obtener beneficios para sus asociados una organización requiere fortaleza, unidad y recursos, los que sólo provendrán de la afiliación. 
Una segunda explicación se basa en la teoría del capital social (Coleman, 1990), donde la asociación se basa en la confianza entre los periodistas y entre cada periodista y el Colegio.

Pero la problemática es mucho más compleja y multicausal, de lo que podría suponerse. Otra elemento concomitante al respecto es la desvalorización de la profesión, a partir de la subvaloración de la importancia y potencial aporte del capital humano y profesional (Soria citado en Gutiérrez y Lavín, 2003), debido a que los profesionales no se especializaron debidamente -aspecto que progresivamente intentan revertir las escuelas de periodismo, con diversos resultados- o se convirtieron en difusores de los gabinetes de prensa.

Aún cuando la represión ejercida sobre los movimientos sindicales, durante el régimen militar, constituyó un retroceso en materia asociativa, no explica completamente el fenómeno. En primer término, porque no todos los países afrontaron regímenes autoritarios, sin embargo en todos ellos se registran bajos índices de asociatividad. Además la dinámica educacional y laboral fuerza a las personas a adquirir una actitud competitiva e individual que inhibe su espíritu asociativo.

También se debe considerar que la liberalización político-económica y educacional, produjo dos efectos. Por una parte, abrió nuevos áreas laborales, pero por otra aumentó la cantidad de egresados de manera inorgánica, alterando la tradicional relación periodistas-medios de comunicación. En el reseñado estudio de Mellado y otros (2005) se verifica que en Región del Bío-Bío el 64\% de los periodistas no trabaja en prensa, desempeñándose en docencia, empresa privada, generadoras de contenido independiente, sociedad civil y organizaciones públicas. Allí reside otra explicación a la baja asociatividad, por cuanto si nos remitimos a los estatutos y prácticas del Colegio, se centra en los problemas de los periodistas de medios de prensa. El discurso del Colegio de Periodistas no evolucionó de una manera tal que acogiera las inquietudes de los profesionales que se desempeñan en esas áreas. Según lo visto hasta ahora, su discurso no va más allá del restablecimiento de la tuición ética, la ley de prensa y el secreto de la fuente.

\section{¿CUÁNTO PUEDEN INFLUIR LOS PERIODISTAS?}

La baja asociatividad en torno al Colegio de Periodistas, plantea dudas respecto a la real vigilancia democrática e injerencia en la vida pública de un gremio debilitado y con bajos índices de asociatividad. En efecto, la nula injerencia del Colegio -tanto en los temas que atañen directamente a sus asociados, como a aquéllos de interés nacional- se debe a que éste opera como sindicato. Entonces, el problema trasciende a una recuperación de ancestrales derechos enajenados o ampliación de garantías legales para ejercer el derecho a la investigación y la vigilancia democrática. Derechos que, por lo demás, una profesión tan desunida no está en condiciones de ejercer, ni un colegio tan debilitado puede presionar para que se cumplan. 
Los resplandores en materia de periodismo de investigación de los últimos años, pese a que muchos discuten no sean más que "periodismo de denuncia", son loables. Sin embargo, estos ensayos de vigilancia democrática son -muy a menudo- intentos de un periodista o un equipo de un programa. Hasta no hay una política editorial sobre esta materia en los medios de comunicación nacionales. Más bien se verifica una práctica de "destapar ollas, sobre las que no hay mayor seguimiento a posteriori y donde, por cierto, la divisoria entre motivaciones democratizantes y comerciales, se vuelve demasiado difusa.

El estado actual de la profesión supone un serio desincentivo a la investigación con fines vigilantes. La saturación del mercado produce que los profesionales velen por la retención de su plaza laboral, antes que por el correcto funcionamiento de la institucionalidad democrática, independiente de si se trata de un colegiado o un no colegiado. En este último sentido, afiliarse al Colegio no representa para el profesional mayor beneficio, salvo un respaldo moral. Y cuando sea importante saber que no está sólo en las luchas democratizantes al momento de enfrentar a la justicia, por haber rozado aunque sea levemente algún interés corporativo, no es mucho lo que podrá ayudarlo ese soporte verbal.

En el mismo sentido, otro de los frenos a la investigación son los excesivos resguardos legales a la dimensión pública de la vida privada de personajes públicos. Aún cuando se acepta que una legislación excesivamente liberal en esta materia, conlleva más riesgos que avances significativos en la democratización de la sociedad y transparencia de las instituciones. No obstante, el afianzamiento democrático en el país permite introducir en la legislación penal y civil mayores espacios para la investigación periodística y sancionar menos prácticas asociadas al proceso.

Desde luego que esas modificaciones no serán introducidas por la clase política, ni menos aún propiciadas por la clase empresarial, por cuanto hacerlo lesiona intereses y los ubicaría en una posición bastante incómoda ante la sociedad civil. Es aquí donde se requiere el actuar de un Colegio de Periodistas fuerte, preocupado por las falencias del proceso democrático, más que por las nimiedades sindicales. Ningún colegio profesional débil y cupular puede ejercer presión alguna, sobre el poder político para lograr avances sustanciales en el ejercicio de la vigilancia democrática.

Más allá del Colegio de Periodistas, el periodista "en su soledad" como señala López Hidalgo (2005) al describir las penurias de los reporteros hispanos, no tiene más sustento para investigar que sus buenas intenciones, y por respaldo, su fe y el teléfono de un buen abogado.

Aunque la fortaleza de una profesión depende más que de su agrupación gremial, ella está llamada a jugar un papel integrador entre sus asociados, el poder político y la sociedad. Por cierto, una gran medida recae en los propios profesionales que debieran cautelar elevar el nivel profesional del periodismo y buscar formas en que la estabilidad laboral no se pague con aislamiento. También atañe a las universidades formar profesionales con mayor integración. 
En este sentido, acudiendo a su formación humanista, los periodistas deben propiciar -desde su plaza laboral- la rearticulación social entre el mundo y quienes controlan la información. Ello exige en el nivel político gremial, desarrollar elementos culturales propios de los trabajadores, como por ejemplo, solidaridad contra individualismo.

En efecto, la pregunta está no en si los periodistas necesitan un colegio profesional-que por cierto lo necesitan- sino en si ese colegio está dispuesto a trabajar para edificar sus exactitudes y acciones en función de la realidad social y laboral contemporánea, y si realmente está interesado en captar al conjunto de comunicadores sociales dentro del mismo arco.

\section{REFERENCIAS BIBLIOGRÁFICAS:}

ARRIETA, Adolfo. (2003) "Mercado de trabajo: organización y representación sindical". Oficina internacional del trabajo. Santiago de Chile.

COLEMAN, J. (1990) Foundations of Social Theory. Harvard University Press. Cambridge.

DADER, José Luis. (2001) La democracia débil ante el populismo de la privacidad. [Online] <http://www.saladeprensa.org/art254.htm> [2005, octubre 21]

ESCOBEDO, Juan Francisco. (2005, septiembre) Periodismo e incertidumbre democrática. Revista Mexicana de Comunicación. Ciudad de México.

GUTIÉRREZ, Fernando \& LAVíN, María del Carmen. (2003). Mercado laboral para periodistas en Concepción. Universidad Católica de la Santísima Concepción, Concepción.

LÓPEZ HIDALGO, Antonio. (2005) El periodista en su soledad. Ediciones Comunicación Social, Sevilla.

MELLADO RUIZ, Claudia. (2005). "Realidad laboral, asociativa y profesional de los periodistas en activo de la octava región, Chile". Proyecto regional financiado por la Dirección de Investigación. Universidad de Concepción - Chile. COD. 205.174.002-1.0 (Investigación en Curso)

NUSSBAUM, David. (2005) "El país debe resolver los temas pendientes de la transparencia" [Online] <http://www.chiletransparente.cl/noticias/alerta.htm> [2005, octubre 21]

(Recibido el 20-03-06, aceptado el 30-06-03) 